\title{
O BRINCAR NA RUA E A TRANSMISSÃO CULTURAL DA BRINCADEIRA DE PIPA
}

Recebido em: $23 / 11 / 2017$

Aceito em: 17/08/2018

\author{
Leys Eduardo dos Santos Soares ${ }^{1}$ \\ Universidade de Pernambuco \\ Universidade Federal da Paraíba \\ João Pessoa - PB - Brasil \\ Elizara Carolina Marin ${ }^{2}$ \\ Universidade Federal de Santa Maria \\ Santa Maria - RS - Brasil \\ Pierre Normando Gomes-da-Silva ${ }^{3}$ \\ Universidade Federal da Paraíba \\ João Pessoa - PB - Brasil
}

RESUMO: Este artigo tem como objetivo analisar como ocorrem a transmissão cultural da brincadeira de pipa e as aprendizagens que estão envolvidas nesse processo nas ruas de um bairro da zona leste de João Pessoa-PB. Trata-se de uma pesquisa descritiva de abordagem qualitativa. A brincadeira foi observada em 16 visitas realizadas nos finais de semana, do mês de dezembro de 2015, período de férias escolares. Foram entrevistadas oito crianças, que foram observadas quando brincavam de pipa. Suas falas foram transcritas e, por meio da Análise de Conteúdo, o estudo revelou que, ao praticar essa brincadeira, as crianças tornam-se agentes culturais que mantêm viva a cultura da pipa e transmitem de modo instruído ou imitativo, as aprendizagens da brincadeira nas ruas investigadas.

PALAVRAS CHAVE: Jogos e Brinquedos. Cultura. Aprendizagem. Atividades de Lazer.

\section{PLAYING ON THE STREET AND THE CULTURAL TRANSMISSION OF THE KITE PLAY}

ABSTRACT: This article aims to analyze how the cultural transmission of kite play and the learning that is involved in this process occur in the streets of a neighborhood in the eastern zone of João Pessoa-PB. This is a descriptive research with a qualitative approach. The play was observed in 16 visits made on the weekends of December of

${ }^{1}$ Doutorando em Educação Física no Programa Associado de Pós-Graduação em Educação Física UPE/UFPB.

${ }^{2}$ Doutora em Ciências da Comunicação. Professora do Centro de Educação Física e Desportos da UFSM.

${ }^{3}$ Doutor em Educação. Professor do Departamento de Educação Física da UFPB. 
2015, during school holidays. 8 children who were observed playing kite, were interviewed. The speeches were transcribed and through the Content Analysis, the study revealed that by practicing this play, children become cultural agents that keep alive the culture of the kite by transmit, in an instructed or imitative way the learning of the game in the streets investigated.

KEYWORDS: Play and Playthings. Culture. Learning. Leisure Activities.

\section{Introdução}

A grande diversidade de jogos e brincadeiras que estão presentes no universo infantil e as experiências que eles possibilitam exercem contribuições importantes para o desenvolvimento social, psíquico e físico. Os jogos e as brincadeiras são práticas características da infância. Gomes-da-Silva (2013) refere que os jogos considerados tradicionais têm, geralmente, uma realização cíclica, isto é, eles vão e voltam, desaparecem e aparecem muitas vezes pelas ruas das cidades, durante um ano ou determinado período de tempo.

Explica Lavega (2013) que os jogos tradicionais podem ser considerados como patrimônio de um povo, devido à forma como são produzidos e vivenciados, e constitui um laboratório social, em que se exige dos sujeitos competências para refazer o material e as brincadeiras que serão vivenciadas nos mais distintos espaços, o que constitui assim um acervo cultural.

A razão pela qual o jogo tradicional resiste ao tempo, em determinada sociedade, é que o jogo está impregnado na vida cotidiana. Para Parlebas (2001), o jogo tradicional é o que é passado de geração em geração, e cujas regras são feitas e desfeitas de acordo com os jogadores. Eles não são praticados em um espaço específico nem têm uma federação que organize campeonatos e regulamente suas normas. De acordo com Marin e Stein (2015), a "tradição" desses jogos deve ser entendida como uma ação criadora. O termo tradição, nos jogos tradicionais, deve ser compreendido como atualização. Isso 
porque, explicam as autoras, esses jogos podem até ter uma origem histórica, mas a cada vez que são transmitidos e praticados, estão sendo ressignificados e reapropriados de acordo com o contexto em que estão sendo realizados. Por exemplo, as crianças que se reúnem na praça para jogar peão inventam novos modos de brincar: estabelecem novas regras, modos de lançar o peão, os locais de lançamento, o sistema de pontuação, tudo realizado de uma nova maneira. Portanto, o que existe é uma atualização, e não, mera reprodução do passado.

Nesse complexo de atualização, em que se mantém viva a tradição dos jogos tradicionais, as crianças são atores fundamentais. Elas são as principais responsáveis pela transmissão cultural desses jogos, que é feita por meio da brincadeira livre e espontânea característica dessa fase de crescimento.

A transmissão cultural diz respeito ao modo como determinado tipo de atividade é passada de geração em geração pelos que participam das atividades. A terminologia 'transmissão cultural' é oriunda dos estudos de Cavalli-Sforza e Feldman (1981). Com base nesse modelo, "a transmissão cultural permite a um grupo perpetuar uma característica nas gerações subsequentes por meio de mecanismos de ensino e aprendizagem" (PONTES; MAGALHÃES, 2003, p.118). De acordo com essa teoria, podemos identificar três tipos de transmissão cultural: a vertical, a horizontal e a oblíqua. A transmissão vertical acontece dos pais para a criança; a horizontal ocorre quando há o envolvimento de pessoas de uma mesma geração (criança-criança ou adulto-adulto); já a oblíqua acontece com gerações diferentes entre não parentes. Porém, Pontes e Magalhães (2003), ao tratar dos jogos tradicionais, referem que a transmissão da cultura da brincadeira é muito mais efetiva quando acontece horizontalmente, ou seja, é de criança para criança. 
Os mais diversos espaços públicos, como praças, bosques e ruas, são territórios do brincar. A rua é um espaço privilegiado, devido ao fato de ser acessível ao público infantil, e um dos principais palcos da experiência lúdica com jogos tradicionais. É nesse espaço onde as crianças estabelecem novas regras, recriam jogos e negociam a forma de utilizá-lo. E todas essas experiências são aprendizagens transmitidas para os demais participantes, por meio de suas habilidades nas brincadeiras, que revelam uma cultura corporal de movimento que caracteriza os modos de participação e as exigências motoras para participar de determinados jogos. Assim, entendemos que as "brincadeiras são como rituais que se transmitem, repetidos ou recriados, em ambientes socioculturais distintos. Via de regra, essa transmissão se dá no próprio grupo de brinquedo, sem interferência adulta, das crianças mais velhas para as menores" (CARVALHO; PONTES, 2003, p.15).

Corroboramos as ideias de Brougère (1998) de que participar de um jogo não significa estar vivenciando a cultura, pois seu primeiro efeito consiste em aprender essa cultura particular, que é a do próprio jogo, porque o jogo tem um universo simbólico particular, que a criança deve aprender a controlar para brincar. Entre as brincadeiras que compõem esse universo dos jogos tradicionais infantis, está a pipa, uma brincadeira milenar que resiste ao tempo e encanta, especialmente, as crianças nos momentos de lazer. Caillois (1990) recorda que, antes de a pipa se tornar um brinquedo, na Europa, no fim do Século XVIII, ela foi utilizada para diversos fins. Na China, por exemplo, foi utilizada para transmitir mensagens simples e medir distâncias, e em Nova-Guiné, como suporte para rebocar embarcações. Como uma brincadeira, a pipa requer habilidades para ser colocada no céu e aprendizagens que estão envolvidas em sua construção, para empiná-la ou, até, participar de uma disputa. 
Com base nesses pressupostos e com o intuito de saber como as aprendizagens são desenvolvidas durante essa brincadeira, objetivamos, neste artigo, investigar como ocorre a transmissão cultural da brincadeira de pipa e quais as aprendizagens que estão envolvidas nesse processo. Dos diversos jogos praticados nas ruas pelas crianças, elencamos a pipa, por ser um dos jogos tradicionais mais praticados ainda hoje nos bairros das grandes cidades. Assim, objetivamos saber como ocorre essa transmissão de aprendizagens desse jogo, investigar as relações entre as crianças que vivenciam a brincadeira, em um bairro do município de João Pessoa-PB, descrever as formas como o jogo se manifesta e analisar suas características singulares.

\section{Métodos}

Trata-se de uma pesquisa descritiva, de abordagem qualitativa, cujos dados foram coletados durante o mês de dezembro de 2015, em ruas próximas à Praça da Amizade, localizada no Bairro do Rangel, em João Pessoa-PB. Foram realizadas 16 visitas às ruas do bairro, em todos os sábados e domingos do referido mês, nos períodos matutino e vespertino.

A coleta dos dados foi dividida em duas etapas: a) a de levantamento, em que se procurou compreender a vivência do brincar de pipa nas ruas do bairro. Para isso, fez-se um levantamento das principais ruas em que era possível observar com frequência o jogo de pipa, registrando os locais de prática e quem eram os praticantes do jogo; b) e a das entrevistas. Depois de feito o levantamento, entrevistamos as crianças que foram observadas brincando de pipa. Utilizamos a entrevista do tipo não estruturada, por ser uma alternativa para entrevistar um público com essa faixa etária e possibilitar uma boa 
flexibilização das perguntas. Além disso, quando necessário, em certos momentos, torna-se uma conversa informal (MARCONI; LAKATOS, 2008).

Nessas ruas, 19 crianças foram observadas quando brincavam de pipa. Oito delas - sete meninos e uma menina, com idades entre sete e dez anos - aceitaram participar das entrevistas, que foram realizadas na mesma rua em que foram vistos brincando de pipa. Durante as entrevistas, utilizamos o recurso do gravador de áudio. As falas das crianças foram transcritas e, com esse material, pudemos inferir os conhecimentos da Análise de Conteúdo (BARDIN, 2011), do tipo categorial temática. Esse tipo de análise "funciona em etapas, por operações de desmembramento do texto em unidades e em categorias para reagrupamento analítico posterior" (SOUZA JUNIOR; MELO; SANTIAGO, 2010, p.34).

De acordo com Bardin (2011), uma vez destacada a categoria analítica, ela pode nos revelar as unidades de contexto e de registro. Como veremos adiante, a unidade de contexto dá um sentido à unidade de registro, na perspectiva de se entender o significado das mensagens. A unidade de registro é uma unidade sintética, em que estão agrupados os segmentos de mensagens, e corresponde à menor base analítica do conteúdo de uma mensagem.

A partir da análise de conteúdo, tendo como referência a identificação das possibilidades de transmitir a cultura do jogo de pipa, identificada nas falas dessas crianças, essas verbalizações foram categorizadas em unidades de contexto e unidades de registro.

Nas unidades de contexto, as falas foram analisadas a partir de duas categorias: a) Aprender a construir: nessa categoria, pode-se saber como a construção das pipas foi transmitida, quem ensinou, onde ensinou e de que maneira esse conhecimento foi 
repassado; b) Aprender a empinar: diz respeito a um saber que está relacionado ao entorno, ao saber brincar socialmente, quais os contratos estabelecidos, quais as regras impostas por aqueles que cruzam, em que lugar se deve soltar a pipa e como subir uma pipa. Para cada unidade de contexto, foram categorizadas duas unidades de registro: Materiais do brinquedo e Confecção do brinquedo, para o Aprender a Construir; E Espaço do jogo e Regras do jogo, para o Aprender a Empinar.

É importante registrar que as falas das crianças foram transcritas seguidas do sexo correspondente, representado pela letra M, para masculino, e F, para feminino, acompanhado da respectiva idade. Quando as crianças faziam referência a outros indivíduos, foram adotados nomes fictícios para preservar a identidade dos investigados.

O projeto que deu origem a esta pesquisa foi aprovado pelo Comitê de Ética em Pesquisa do CCS/UFPB (protocolo $n^{\circ} 0262 / 15$ ).

\section{Resultados e Discussão}

\section{Aprender a Construir}

Durante as observações, constatou-se que, quando as crianças brincavam de pipa, sua primeira atitude foi de se esforçar para construí-la. A partir de então, foi possível identificar a unidade de registro 'Materiais do brinquedo', porque, para construir seu brinquedo, as crianças precisam de certos materiais, que, muitas vezes, são adquiridos nas ruas do próprio bairro e nas residências das crianças, como demonstram suas falas:

Os palitos eu consigo no pé de coco, é só descascar as folhas e tirar os palitos (M10). 
Eu aprendi a fazer a pipa com o Jonas, tem que ter papel, cola, linha e uma sacola. Eu pego tudo lá em casa... tem tudo...papel, sacola... a linha eu pego da minha mãe (M7).

Percebemos que a maioria dos materiais que as crianças utilizam são reutilizáveis, isto é, podem ser utilizados para outra finalidade, como é o caso da sacola plástica e da linha de costura, que passam a ter outra função nas mãos das crianças.

Eu uso garrafa de refrigerante, tem que quebrar o vidro e bater nele até ficar bem fininho... como um pó. Eu aprendi isso com o Marcelo (M8).

Vejamos que a aquisição desses materiais só aconteceu porque as crianças foram instruídas por outra criança sobre quais os materiais eram necessários para fabricar a pipa. Isso porque, na maioria das vezes em que foram observadas, percebeu-se que elas não faziam o brinquedo na rua sozinhas, muito menos que os materiais encontrados não fossem compartilhados, como o cerol, que, quando sobra, é dividido com os outros para que também possam brincar.

Para fazer o cerol, eu faço com o Marcelo. A cola a gente compra, o vidro nós procuramos garrafas pelas ruas e quebramos. Depois de misturar é só passar na linha (M8).

$\mathrm{Eu}$ pego as garrafas vazias em casa. Faço o cerol na rua mesmo, porque minha mãe não gosta que eu faça dentro de casa (M8).

De acordo com Benjamin (1984), é com os materiais que as crianças têm ao seu redor que elas exercem uma importante experiência de perceber o entorno ao reutilizar os restos de material utilizado pelos adultos. Elas dão uma nova utilidade a esses objetos e, como atores desse processo, inserem-se como artesões do brincar, mantêm viva a cultura do jogo e repassam para seus pares o conhecimento sobre como fabricar a pipa. Esse é um segundo tipo de aprendizagem derivada do aprender a construir e que envolve a manipulação dos materiais para fazer o brinquedo. Inicialmente, as crianças 
buscam os materiais, depois, manipulam essa matéria-prima e produzem o objeto. Essa é a segunda unidade de registro denominada de 'Confecção do brinquedo'. Em suas falas, as crianças indicam os modos como põem em prática os conhecimentos para confeccionar suas pipas manipulando material reutilizável:

Se não tiver papel seda, eu cubro a pipa com sacola e fica bom do mesmo jeito (M7).

Quando não tem linha 10 eu uso linha de costura, dá para soltar... Faço a rabada ${ }^{4}$ também com ela (M10).

Esses discursos expressam que as crianças usam sua criatividade para dar um novo significado a determinado tipo de material, pois, como referiram, quando não dispõem do material específico para fazer a pipa, utilizam materiais alternativos, como, por exemplo, o papel seda substituído por sacola, e a linha 10, que também foi substituída por linha de costura. Isso corrobora o pensamento de Gomes-da-Silva (2013, p.75) de que "transformar as coisas do cotidiano em brinquedos e modificar as regras, para aproveitar melhor o jogo, forma o brincante, na medida em que o faz experimentar a aventura do refazer" (GOMES-DA-SILVA, 2013, p.75).

Ao tentar refazer determinado objeto com materiais do cotidiano, as crianças se assumem como continuadores da tradição de uma cultura do brincar, como foi percebido nas pipas utilizadas pelos investigados, pois o fato de algumas não possuírem determinado material específico de melhor qualidade e mais bonito esteticamente não as impediu de praticar.

A originalidade está no fato de que cada pipa construída pela criança tem uma nova peculiaridade, um novo formato, uma nova maneira de construir, um refazer original, em que as crianças também se empenham para deixar o brinquedo bonito

\footnotetext{
${ }^{4}$ Linha com tiras de sacolas, que é presa na parte inferior da pipa. Também conhecida como rabiola.
} 
usando o material de que dispõem. Por isso, Brougère (2004, p.23) nos afirma que “criar um brinquedo é propor uma imagem que vale por si mesma e que dispõe, assim, de um potencial de sedução, que permite ações e manipulações, em harmonia com as representações sugeridas". Quando as crianças aprendem a construir seus brinquedos e a utilizar os mais diversos materiais para adaptar o objeto de acordo com suas possibilidades, também estão manipulando um mundo simbólico, que está impregnado na brincadeira de pipa.

Em algumas falas, foi possível notar que aprender a construir a pipa depende de aprendizagens adquiridas com o outro. Essas aprendizagens podem ser oriundas de uma criança mais velha ou mais experiente, que ensina os passos iniciais para a confecção do brinquedo.

Eu aprendi a soltar aqui na rua com Caio, Vinicius e Ítalo, eles me ensinaram a fazer. No começo eles me ajudaram, ai foram me dizendo como era, depois eu fiz tudo sozinha (F10).

Com o Jonas eu aprendi o macete de amarrar a linha do cabrecho ${ }^{5}$, no começo eu não sabia fazer sozinho (M7).

Tomasello; Kruger e Ratner (1993) mencionam três tipos de aprendizagem cultural: a aprendizagem imitativa, a instruída e a colaborativa. A aprendizagem imitativa ocorre quando a criança observa o comportamento de outra e analisa seu modo de agir, de maneira a reproduzir essas ações de acordo com a atividade que está sendo desenvolvida. A aprendizagem instruída acontece quando a criança recebe algum tipo de instrução para fazer a atividade. Geralmente essa instrução é dada por indivíduos mais velhos ou com mais experiência e habilidade em determinada atividade. Já a aprendizagem colaborativa existe quando há um grupo que, em cooperação, busca atingir determinado objetivo e se organiza nas tarefas para alcançar uma meta.

\footnotetext{
${ }^{5}$ Parte de linha que prende a pipa à linha do carretel do jogador.
} 
Assim, o ato de construir uma pipa envolve aprendizagens que foram adquiridas de modo instruído por meio de outras crianças, que foram capazes de ensinar aos menos experientes os modos de fazê-la:

O rabada é fácil de fazer, quem me ensinou foi o Marcelo. Tem que cortar a sacola em tiras e quando for amarrar na linha tem que deixar um espaço (F10).

Podemos inferir que esse processo de transmissão e construção do brinquedo “diz respeito a colocar-se na cadeia da cultura. É fazer-se parte das construções do mundo humano; é constituir-se como continuador da tradição, como partícipe da experiência humana do brincar no mundo" (GOMES-DA-SILVA, 2013, p.74). Na brincadeira de pipa, não basta saber empinar, é preciso, antes, esforçar-se para conseguir o material necessário para confeccionar seu objeto, porque fazer o próprio brinquedo significa deixar marcas pessoais em brinquedos e brincadeiras socialmente difundidos.

\section{Aprender a Empinar}

Depois de finalizado o processo de construção da pipa, as crianças utilizam um tipo de aprendizagem derivada dos conhecimentos sobre como empinar, também transmitidos culturalmente pelas próprias crianças que participam das brincadeiras de rua. Elas precisam conhecer o "espaço do jogo". Nesse contexto, as aprendizagens transmitidas foram essenciais para entrar na brincadeira, pois é preciso saber onde empinar, qual o local mais adequado e quais os cuidados necessários com o entorno. As falas seguintes confirmam essa assertiva:

Tem que ver onde tem fio... Tem que ter cuidado com os fios, se tiver muito fio não é bom soltar perto (M8).

O melhor local é a rua, mas às vezes a pipa fica presa nos fios, tem que fazer a pipa ficar distante deles (M7). 
Nessas falas, percebe-se que a rua é o local privilegiado da brincadeira, porém os fios de alta tensão podem fazer com que a linha da pipa seja partida ou a pipa fique enrolada no fio, o que faz com que as crianças tenham receio de perdê-la. A brincadeira de pipa é também uma experiência para enfrentar o medo de perder a pipa, seja pelo fio, seja durante um "cruza". Um "cruza" é o momento em que dois participantes disputam a permanência no céu. Por intermédio da pipa, eles tentam cortar a linha do oponente, e quando a disputa é aceita, geralmente termina com um ganhador e um perdedor. Segundo Brougère (2004), durante as brincadeiras, as crianças constroem relações de posse e de perda, em que o brinquedo fabricado por ela tem um investimento afetivo, então, perdê-lo é também perder parte de si, porque possuir uma pipa é ter o direito de participar do jogo, e quem não tem apenas observa a brincadeira na tentativa de conseguir pegar uma que caia.

Em seu estudo, Melo (2006) constatou que a pipa é um objeto feito para que a criança experimente intensas vivências e relações de aquisição e de perda, negociando o local de jogo. Isso porque a rua é um local público, e as pipas devem manter certa distância entre elas (quando não se deseja cruzar). Para isso, as crianças negociam o espaço de jogo que deve ser respeitado por quem empina pipa na mesma rua. Essa é uma forma de regular os modos de conviver, para que todos possam usufruir do espaço, porquanto convivendo no mesmo espaço é que as aprendizagens são transmitidas.

Eu aprendi com o meu irmão aqui na rua, vendo ele soltar, ele fazia aí eu observava como era, e na hora de subir tinha que ter cuidado com os fios (M8).

Da primeira vez foi Marcelo quem me ensinou a soltar na rua, fui aprendendo com ele, ele cruzava muito não perdia pra ninguém... fui vendo e depois eu consegui empinar sozinho (M7). 
Em suas falas, as crianças expressam que, aprender a empinar não requer aprendizagens adquiridas de modo instruído, como ocorreu no aprender a construir. Nessa unidade, retomando as ideias de Tomasello; Kruger e Ratner (1993), as aprendizagens transmitidas estão mais relacionadas ao imitativo, porque, nas falas, fica claro que a criança só consegue empinar uma pipa porque observou outra realizando os movimentos. Para o ato de empinar, não é necessário que outra criança passe as instruções. Quando estão empinando a pipa, as crianças menos experientes põem em prática o que aprenderam observando na rua e põem em prática habilidades como correr e puxar a pipa, ganhar vento segurando o carretel e liberando a linha. Na aprendizagem imitativa, a criança aprende observando outros sujeitos e seu esquema de ação motora e tenta reproduzi-lo.

Explica Tomasello (2000, p.38) que, para transmitir a tradição cultural da brincadeira de pipa, "a aprendizagem imitativa é a chave para esse processo porque permite aos indivíduos adquirirem os usos de artefatos e outras práticas de seus grupos sociais de maneira relativamente fiel". Ao observar as outras crianças mais experientes colocando a pipa para voar, elas aprendem que devem desempenhar um senso lógicoespacial para perceber o local onde deve empinar a pipa e guiá-la considerando a força e a direção do vento. De maneira geral, trata-se das habilidades perceptivas e motoras que precisam ser desempenhadas para colocar a pipa no ar.

Tem que correr rápido, se não correr a pipa não sobe, e também tem que saber soltar a linha, se não ela não vai subir (F10).

Você deve ficar olhando o céu por todos os lados para ver se alguma se aproxima (M7).

Um segundo tipo de saber relacionado ao empinar pipa tem a ver com a participação efetiva da criança no jogo, ao momento em que a pipa foi colocada no ar. 
Trata-se de aceitar regras e os contratos sociais estabelecidos, são as 'regras do jogo', a segunda unidade de registro. Quando a pipa está no céu, a brincadeira tem algumas regras a serem aceitas para quem desejar participar dela. Assim como qualquer outro participante pode iniciar um cruza com outra pipa que esteja no ar, quando a linha de uma das pipas é cortada e cai do céu, qualquer pessoa pode pegá-la, e quem conseguir é considerado seu novo dono:

Quem tiver na rua pode pegar... quem tiver olhando o cruza, corre todo mundo (M8).

Quando os meninos estão cruzando fica todo mundo olhando, aí quando a pipa voa todo mundo vai atrás (M7).

Percebe-se, nessas falas, que as crianças aprendem as regras do jogo à medida que vão participando dele. No jogo de pipa, os participantes não discutem sobre regras, e quando uma pipa é colocada no ar, todos sabem que pode acontecer um cruza, mesmo que esse participante deseje brincar sozinho, sem arriscar perder sua pipa. Nesse caso, a aprendizagem cultural das regras desse jogo ocorre de maneira imitativa, segundo a definição de Tomasello; Kruger e Ratner (1993).

Todo mundo já sabe, se colocar no céu, alguém pode vir e cortar, tem que tomar cuidado...prestar atenção (F10).

Essas falas denotam que algumas regras do jogo de pipa tendem a ter um aspecto universal, isto é, são reconhecidas sem que seja preciso discutir sobre elas antecipadamente. Quando alguma criança coloca uma pipa no céu, ela "já sabe" que alguém pode cortá-la, e ela perder seu brinquedo. Esses participantes sabem da regra porque já observaram alguma vez que é assim que o jogo funciona e brincam seguindo as regras que aprenderam observando os outros jogarem. E como tanto a rua quanto o 
céu são lugares públicos, quando uma pipa está voando sem controle, passa a ser de domínio público, portanto o dono não pode reivindicá-la posteriormente.

Melo (2010, p.96) afirma que "aí está justamente um dos pontos de relevância no estudo das pipas, pois a aprendizagem de construí-la e lançá-la ao vento nunca careceu de nenhuma sistematização. Há algo que resiste, pela via do lúdico e do informal, que garante sua manutenção". Por isso percebemos que os grupos de crianças que brincam de pipa espontaneamente nas ruas são agentes de cultura, propagadores de saberes transmitidos de criança para os demais participantes.

No ato de empinar a pipa, a brincadeira é um fenômeno grupal, porque não são somente as crianças que estão com uma pipa no ar que participam do jogo, mas também as que estão nas esquinas observando, à espera de conseguir uma pipa para também brincar, pois, quando alguém empina uma pipa, centraliza um núcleo de observadores que, às vezes, comentam histórias e provocam o jogador (PONTES et al., 2003).

Eu já peguei uma que voou um dia, tive que correr e chegar primeiro, porque todo mundo que ficava só olhando corre também para pegar (M8).

A regra de quem pegar a pipa que cai do céu torna-se proprietário dela é um contrato lúdico estabelecido por aqueles que participam da brincadeira. De acordo com Parlebas (2001, p.95), o contrato lúdico é "um pacto de fundação de uma microssociedade, certamente provisória, intermitente e restringida, mas que não deixam de ser realizadas ações cheias de complexidade de acordo com uma lei livremente aceita”. Essas regras envolvem o ato de cruzar uma pipa e pegá-la quando ela estiver caindo do céu e foram transmitidas culturalmente de modo imitativo. Não foi necessário estabelecer os modos de executar o jogo. E embora o contrato lúdico seja simbólico, foi 
repassado entre as crianças de modo imitativo, a partir das experiências delas mesmas com o jogo, brincando na rua e observando as que são mais experientes.

\section{Considerações Finais}

Diante do exposto, podemos afirmar que existem aprendizagens inerentes aos que participam da brincadeira de pipa, como os modos de confeccionar o brinquedo, a reutilização de materiais, a técnica de empinar a pipa, adquiridas por via de transmissão oral.

Em suas falas, as crianças entrevistadas demonstraram que brincar de pipa é uma forma de adquirir aprendizagens, que elas podem transmitir para seus pares, seja de modo imitativo, em que observam as ações do outro e, depois, tentam reproduzi-las no empinar, ou de modo instruído, em que uma criança geralmente é responsável por ensinar a como construir a estrutura e os implementos da pipa.

Notamos que, para brincar de pipa, primeiro, as crianças adquirem o material por vias informais, de acordo com suas possibilidades financeiras - quem tem dinheiro compra, quem não tem busca outros materiais para reproduzir o mesmo brinquedo. $\mathrm{O}$ esforço justifica sua necessidade de brincar. Tamanha é a determinação que não há impedimentos financeiros e materiais para a realização da brincadeira, pois, quando falta determinado material, outro é reutilizado.

A pipa traz o advento dos reutilizáveis manufaturados. Nesse sentido, é necessária uma força imaginativa para adaptar os objetos, como foi o caso, nesta pesquisa, das pipas de papel. O jogo de pipa tem essa particularidade de ser uma brincadeira que exige um esforço anterior, para adquirir e substituir materiais - seda, por sacola, e linha 10, por linha de costura. Tudo é aprendido e compartilhado com os 
outros nas ruas, que são lugares de compartilhamento de aprendizagens por meio da brincadeira, territórios do aprender, que regulam os modos de conviver, até porque a brincadeira de pipa tem como princípio conquistar o território, ela é territorial. Deve-se ser o melhor da rua para permanecer no espaço. O desafio consiste em ser o melhor do céu, para que ninguém se atreva a infiltrar naquele espaço. Por isso, podemos compreender que construir e empinar são aprendizagens culturais do brincar infantil transmitidas nas ruas, a tradição de uma cultura lúdica, que é renovada a cada saber compartilhado e a cada pipa que ganha voo.

\section{REFERÊNCIAS}

BARDIN, L. Análise de conteúdo. São Paulo: Edições 70, 2011.

BENJAMIN, W. Reflexões: a criança, o brinquedo e a educação. São Paulo: Summus, 1984.

BROUGÈRE, G. Brinquedo e cultura. São Paulo: Cortez, 2004. 1998. . A criança e a cultura lúdica. Rev. Fac. Educ., São Paulo, v.24, n.2, Jul./Dez.,

CAILLOIS, R. Os jogos e os homens: a máscara e a vertigem. Lisboa: Cotovia; 1990.

CARVAlHO, A. M. A.; PONTES, F. A. R. Brincadeira é cultura. In: CARVALHO, A. M. A. et al. Brincadeira e cultura: viajando pelo Brasil que brinca. v. 1. São Paulo: Casa do Psicólogo, 2003.

CAVALLI-SFORZA, L. L.; FELDMAN, M. W. Cultural transmission and evolution: a quantitative approach. New York: Princeton University Press, 1981.

GOMES-DA-SILVA, P. N. (Org.). Oficina de brinquedos e brincadeiras. Petrópolis: Vozes, 2013.

LAVEGA, P. Os jogos tradicionais como patrimônio cultural mundial. In: MARIN, E. C.; RIBAS, J. F. M. Jogo tradicional e cultura. Santa Maria: UFSM, 2013.

MARCONI, M. A.; LAKATOS, E. M. Técnicas de pesquisa: planejamento e execução de pesquisas, amostragens e técnicas de pesquisa, elaboração, análise e interpretação de dados. 7. ed. São Paulo: Atlas, 2008. 
MARIN, E. C.; STEIN, F. Jogos tradicionais e manifestações coletivas: relações de conflito entre tradição e modernidade. Pensar a prática, Goiânia, v. 18, n. 4, out./dez. 2015.

MELO, M. F. A. Q. Voando com a pipa: esboço para uma psicologia social do brinquedo à luz das ideias de Bruno Latour (Tese de Doutorado). Programa de PósGraduação em Psicologia Social, Centro de Educação e Humanidades - UERJ. Rio de Janeiro/São João Del Rei, 2006, 410 fls.

Algumas aprendizagens construídas durante a brincadeira de pipa: o que está em jogo. Educação em Revista, Belo Horizonte, v.26, n.02, p.89-116, ago. 2010.

PARLEBAS, P. Juegos, deporte y sociedad: léxico de praxiología motriz. Barcelona: Paidotribo, 2001.

PONTES, F. A. R.; MAGALHÃES, C. M. C. A Transmissão da cultura da brincadeira: algumas possibilidades de investigação. Psicologia: reflexão e crítica, v. 16. n 1, p.117124, 2003.

PONTES, F. A. R. et al. Guerra no ar: tradição e cultura do papagaio de Belém. In: CARVALHO, A. M. A. et al. Brincadeira e cultura: viajando pelo Brasil que brinca. v. 2. São Paulo: Casa do Psicólogo, 2003.

SOUZA JÚNIOR, M. B. M.; MELO, M. S. T.; SANTIAGO, M. E. A análise de conteúdo como forma de tratamento dos dados numa pesquisa qualitativa em Educação Física escolar. Movimento, Porto Alegre, v. 16, n. 03, p. 31-49, jul./set. 2010.

TOMASELlO, M.; KRUGER, A. C.; RATNER, H. H. Cultural learning. Behavioral and Brain Sciences, v.16, p. 495-552, 1993.

n.2, April 2000.

Culture and cognitive development. American Phychological Society, v.9,

\section{Endereço dos Autores:}

Leys Eduardo dos Santos Soares

Rua Alípio da Cunha Machado, 1643, Rangel

João Pessoa - PB - 58.070-150

Endereço Eletrônico: leyseduardo@hotmail.com

Elizara Carolina Marin

Universidade Federal de Santa Maria

Centro de Educação Física e Desportos

Departamento de Desportos Individuais

Campus Universitário

Santa Maria - RS - 97.105-900

Endereço Eletrônico: elizaracarol@yahoo.com.br 
Pierre Normando Gomes-da-Silva

Universidade Federal da Paraíba

Centro de Ciências da Saúde - Campus I

Departamento de Educação Física - Castelo Branco

João Pessoa - PB - 58.000000

Endereço Eletrônico: pierrenormandogomesdasilva@gmail.com 